\title{
O PROCESSO DE REGULARIZAÇÃO FUNDIÁRIA DE TERRAS QUILOMBOLAS E SUAS IMPLICAÇÕES
}

\author{
THE PROCESS OF LAND REGULARIZATION OF QUILOMBOLAS LANDS AND \\ THEIR IMPLICATIONS
}

\author{
Vilson Pereira dos Santos ${ }^{1}$ \\ Veneranda Ferreira Nunes ${ }^{2}$
}

RESUMO: A regularização fundiária das terras pertencentes às comunidades remanescentes de quilombos é tema polêmico envolvendo interesses políticos e sociais que afetam diretamente aos seus cidadãos que foram/são historicamente excluídos das ações governamentais. A escolha em investigar o processo de regularização das terras quilombolas do Estado do Tocantins se deu pelo fato dessa regularização acontecer por meio de muitos conflitos em torno da terra. As implicações territoriais estão implícitas no embate entre o lado mais fraco dessa disputa que são os quilombolas e os latifundiários que tentam a qualquer custo desalojar os aquilombados. Equacionar, estudar e produzir reflexões sobre esses problemas talvez possa contribuir para enriquecer a discussão dos processos de regularização fundiária das terras quilombolas. Tendo em vista essa problemática foi realizada uma pesquisa de cunho qualitativo que objetivou analisar o processo de regularização fundiária das terras quilombolas no Estado do Tocantins e suas implicações territoriais. Para a discussão teórica acerca da regularização fundiária das terras quilombolas foram utilizadas fontes bibliográficas como Maestri (2005), Santos (2013); Fiabani (2005), INCRA (2020) dentre outros.

Palavras-chave: Conflitos. Regularização. Terras Quilombolas.

ABSTRACT: The land tenure regularization of lands belonging to the remaining quilombo communities is a controversial issue involving political and social interests that directly affect their citizens who have been / are historically excluded from government actions. The choice to investigate the process of regularizing quilombola lands in the State of

\footnotetext{
I Mestre em Educação pela Pontifícia Universidade Católica de Goiás (2012), graduado em Geografia pela Fundação Educacional de Caratinga - FUNEC, graduado em História pela Universidade Federal do Tocantins (2006), Graduado em Pedagogia pela Faculdade São Marcos - FASAMAR (2012), especialista em História e Cultura Africana e do Negro no Brasil pela Universidade Federal do Tocantins (2010), é professor da Faculdade São Marcos - FASAMAR (2020-atual), foi professor substituto do curso de História da Universidade Federal do Tocantins (2013-2015) atuando no Campus de Porto Nacional, professor da educação básica do Governo do Estado de Tocantins (2011-atual). Tem experiência em Estágio Supervisionado e na área de História, com ênfase em História do Brasil, atuando principalmente no seguinte tema: escravidão, castigos, violência e em Educação de Jovens e Adultos nos temas: direito à educação e evasão escolar.

${ }^{2}$ Formada em pedagogia com pós-graduação em psicopedagogia e Metodologias, e Práticas Educativas do Ensino Fundamental pela Faculdade Campos Elísio- FCE. Atualmente trabalha na Educação de Palmas Tocantins. E-mail: veneranda.nunes7@gmail.com.
} 
Tocantins was due to the fact that this regularization happened through many conflicts over the land. The territorial implications are implicit in the clash between the weakest side of this dispute, which are the quilombolas and the landowners who try at all costs to dislodge the landlords. Equating, studying and producing reflections on these problems may perhaps contribute to enrich the discussion of the processes of land regularization of quilombola lands. In view of this problem, a qualitative research was carried out that aimed to analyze the process of land regularization of quilombola lands in the State of Tocantins and its territorial implications. For the theoretical discussion about the land regularization of quilombola lands, bibliographical sources were used, such as Maestri (2005), Santos (2013); Fiabani (2005), INCRA (2020) among others.

Keywords: Conflicts. Regularization. Lands. Quilombolas.

\section{INTRODUÇÃO}

A escravidão de negros foi um dos episódios mais marcantes do Brasil, uma vez que marcou a história do país pela forma como foram tratados homens e mulheres negros escravizados que viveram entre o trabalho forçado, a resistência à escravidão e os castigos físicos a que eram submetidos. Uma das muitas formas de resistência era a fuga para terras distantes e isolados onde formavam quilombos.

Há uma luta secular pelo direito e legalização das terras pertencentes ao povo remanescentes de quilombos. O sinal de reconhecimentos dos seus direitos à terra foi determinado pela Constituição Federal de 1988 sendo grande avanço. Porém, pouca coisa mudou nesses mais de 30 anos.

Nesse sentido, esta pesquisa bibliográfica que originou o presente trabalho objetivou analisar o processo de regularização fundiária das terras quilombolas do Estado do Tocantins.

A estrutura deste trabalho está organizada em duas partes principais: a primeira referese ao contexto do Brasil escravista referenciando a fuga como resistência e a formação dos quilombos históricos e os avanços conquistados pela Constituição Federal de 1988. A segunda parte trata-se da luta e conflitos relacionados à regularização fundiária das terras quilombolas do Estado do Tocantins e suas implicações.

\section{A RESISTÊNCIA DO NEGRO À ESCRAVIDÃO E A FORMAÇÃO DOS QUILOMBOS NO BRASIL ESCRAVISTA}

A história dos quilombos remota ao período colonial brasileiro que utilizou, em grande escala, a mão-de-obra escrava negra. Os quilombos foram resultados da luta dos cativos pela liberdade, considerado o êxito da resistência das pessoas escravizadas. A resistência escrava era ocasionada pela condição de escravo dos negros e, principalmente, pelos castigos e privações que sofriam. Durante o longo período escravista ocorrido no Brasil, a violência foi uma das características mais marcantes desse sistema socioeconômico (Cf. FIABANI, 2005). Santos (2013), afirma que: 
$\mathrm{Na}$ violência implícita à escravidão aponta-se uma parcela importante e imprescindível da dominação dos senhores sobre seus escravos no interior das diversas unidades produtivas existentes no decorrer da sociedade escravista brasileira. A prática da violência foi imposta com o intuito de submeter e controlar as ações de negação dos cativos frente à sociedade que os oprimia e os dominava (SANTOS, 2013, p. 2394).

O castigo imposto ao escravo infrator apresentava-se como parte do "governo econômico dos senhores", aliado ao trabalho excessivo e à alimentação insuficiente. Essas condições sub-humanas levavam as pessoas, submetidas à escravidão, a empreender a fuga em busca da tão sonhada liberdade. Mas, os quilombos não foram a única forma de resistência dos escravos à escravidão. Fiabani (2005) aponta outras formas de resistências como:

[...] o suicídio que é a resistência dos fracos, mas que se fundamentava em uma concepção religiosa - a ideia de que depois da morte a alma voltaria ao país dos antepassados; o aborto voluntário das mulheres, com o fito de poupar os seus filhos do jugo da escravidão; o envenenamento dos senhores brancos, com a ajuda de plantas toxicas, a sabotagem do trabalho; a revolta e a fuga por fim (p. 12I).

A fuga, quando bem sucedida, resultava quase sempre na formação de um quilombo. Era nos quilombos que os "fujões", agrupados, se protegiam dos ataques dos escravizadores e animais selvagens. Outras formas de resistência dos negros à escravidão existiram, mas, com certeza a fuga foi a que mais se aproximava da liberdade. Fiabani (2005) afirma que " $a$ fuga foi uma das formas de resistência do cativo que mais preocupou a sociedade escravista" (p. 22). De acordo com Maestri (2005):

[...] fugiam trabalhadores escravizados, de ambos os sexos, crianças, jovens, adultos ou já idosos; fugiam cativos das cidades, das residências, das embarcações, das chácaras, das fazendas, das olarias, das charqueadas. Fugia o cativo crioulo, que não conhecia outra vida que a vivida no jugo da escravidão, fugia o africano apenas ou há muito chegado ao Brasil, que vivera em liberdade no Continente Negro. Fugia o cativo doméstico, o trabalhador do eito, o ganhador especializado (MAESTRI, 2005, p. or).

Sobre as fugas de escravos dos engenhos, Almeida (2002) afirma, também, que:

As fugas não eram empreitadas fáceis, os lideres surgiam na organização e no ato de escapar. Todas as condições empurravam esses trabalhadores a rigorosos sistemas de defesa, viviam na clandestinidade e alguns com marcas dos seus senhores no corpo, não podiam se expor em demasia (ALMEIDA, 2002, p. 97)

Ainda na concepção de Almeida (2002), o sistema de produção social do trabalho escravo tinha características de "[...] extrema violência, jornadas de trabalho de I6 a I8 horas, suplícios, torturas e toda a sorte de maus tratos. Ele próprio vai [...] engendrar o seu contrário - os quilombos" (ALMEIDA, 2002, p. 93).

Nesse sentido, surgia, em todo o território brasileiro, quilombos que abrigavam escravos fugidos e tornava unidades de resistência à escravidão. $\mathrm{O}$ quilombo era um local de refúgio que abrigavam escravos fugidos, negros e mestiços, havendo, ainda, uma minoria de indígenas e brancos pobres ou que deviam para a justiça. Segundo Piletti (I99I) o quilombo era "[...] toda habitação de negros fugidos que passem de cinco, em parte despovoada, ainda que não 
tenham ranchos levantados nem se achem pilões neles" (PILETTI, I99I, p. 65). Já para Fiabani (2005) o quilombo:

[...] representou uma afirmação da oposição do produtor feitorizado contra o escravismo, produto da singularidade desse tipo de sociedade. De um lado, estavam os trabalhadores negros lutando contra a expropriação de sua força de trabalho. Do outro, a classe escravista empenhada no retorno dos produtores à escravidão. $O$ quilombo foi uma clara expressão da luta de classes na produção colonial (p. 24).

Os quilombos localizavam-se em áreas próximas aos engenhos, mas, de difícil acesso. A sua localização era estratégica. Pois, eram de difícil acesso para dificultar as incursões militares que eram enviadas com a finalidade de destruí-los. Ficavam próximos dos engenhos para poder manter relações comerciais, não com os senhores, mais com os comerciantes das várias vilas e cidades que se formavam próximas aos engenhos a fim de abastecer o quilombo com ferramentas de trabalho, armas, etc.

Nesse sentido, Fiabani (2005) afirma que:

[...] as vilas vizinhas, entregues à monocultura ou sujeitas à precariedade da lavoura de mantimentos, socorriam-se dessa atividade polimorfa dos negros aquilombados. Os frutos da terra, os animais de caça e pesca, a cerâmica e a cestaria dos negros trocavam-se ferramentas industriais e agrícolas, roupas, armas de fogo e outros produtos de manufatura (p. 72).

Os escravos aquilombados praticavam a "[...] agricultura, artesanato, caça, coleta, extrativismo, pesca, rapinagem, serviços, etc.” (FIABANI, 2005, p. II). Mas, não muito frequente, os quilombolas utilizavam da força física para adquirir bens produzidos fora dos seus domínios. Mas, davam mais preferência ao escambo ${ }^{3}$ com comerciantes e pessoas que eram igualmente marginalizados.

Nesse sentido, os quilombos mantinham certa aproximação das áreas urbanas, pois, essa aproximação facilitava além das transações comerciais, o auxílio na fuga de escravos. Sobre essa interação Almeida (2002) afirma que:

\begin{abstract}
A interação com grupos oprimidos - na figura dos camponeses pobres, vaqueiros, desertores, pequenos comerciantes, entre outros - gera um fluxo de contatos e transações comerciais que vão se ampliando e consolidando proporcionalmente ao crescimento organizacional do quilombo (ALMEIDA, 2002, p. 97).
\end{abstract}

Essas trocas comerciais fortaleciam a resistência dos quilombos, uma vez que os quilombolas adquiriam, além de produtos básicos para suas sobrevivências, armas de fogo que eram fundamentais para sua defesa. As armas de fogo equilibravam um conflito armado entre os quilombolas e as forças militares enviadas para acabar com os quilombos. Sobre a defesa dos quilombos, Fiabani (2005), afirma que:

3 O Escambo é uma transação comercial, muito comum no período colonial, pela qual as partes envolvidas trocavam ou permutavam bens ou serviços em forma de crédito sem o envolvimento de dinheiro. 
[...] os quilombolas desenvolveram técnicas de combate e estratégias que permitiram êxito em muitos enfrentamentos com a sociedade repressora. Muitas vezes, profundos conhecedores do ambiente, construíram caminhos alternativos, enganando os inimigos. Quando em desvantagem numérica, evitavam o enfrentamento direto com as forças escravistas, construindo, entretanto, cercas, fossos e paliçadas para protegerem o mocambo (FIABANI, 2005, p. 24)

No Brasil, onde havia escravidão com certeza existiam quilombos. Eles eram resultados da resistência à escravidão. Dos diversos quilombos existentes no Brasil, o maior e mais famoso foi o de Palmares, localizado na Capitania de Pernambuco, numa região conhecida como Serra da Barriga, hoje pertencendo ao Estado de Alagoas.

Palmares viveu seu apogeu na segunda metade do século XVII. Foi um verdadeiro Estado Negro dentro da colônia portuguesa. Mas, as primeiras referências sobre a existência de um quilombo na região remontam a 1580 . Sua formação era de escravos fugidos das Capitanias de Pernambuco e Bahia. Já no final do século XVII, esse quilombo ocupava uma vasta área coberta de palmeiras e se estendia do cabo de Santo Agostinho ao Rio São Francisco (Cf. FIABANI, 2005). A denominação de Palmares ocorreu devido à grande quantidade de palmeiras na região.

Não se pode negar a importância histórica do Quilombo dos Palmares para a historiografia brasileira por sua grandeza até o seu fim. Porém outros tantos quilombos históricos existiram e tiveram grande importância na representatividade da resistência escrava. E esses tantos outros quilombos resistiram a ataques, invasões, grilagem de suas terras e ao próprio tempo resistindo até os dias atuais como comunidades remanescentes de quilombos.

\section{A REGULARIZAÇÃO DAS COMUNIDADES QUILOMBOLAS E SUAS IMPLICAÇÕES}

A escravidão de negros foi um dos episódios mais marcantes do Brasil, uma vez que marcou a história do país pela forma como foram tratados homens e mulheres negros escravizados que viveram entre o trabalho forçado, a resistência à escravidão e os castigos físicos a que eram submetidos.

Muitas vezes homens e mulheres negros escravizados, revoltados com sua condição de cativos, fugiam de seus senhores, chegando a organizar-se em quilombos, cujo principal, o de Palmares no nordeste brasileiro, conseguiu tornar-se um verdadeiro estado negro dentro da colônia portuguesa (Cf. ALMEIDA, 2002).

Após mais de 300 anos, finalmente em 1888 é promulgada a Lei Áurea que declara extinta a escravidão negra no Brasil. A Lei Áurea não trouxe nenhum benefício à população afrodescendentes além da liberdade vivendo à margem da sociedade excluídos de todas as políticas públicas e direitos mesmo que formalmente livres. Passando de mercadorias de grande valor para seus proprietários a seres humanos sem valor algum perante a sociedade brasileira. A igualdade material demorou muito para ser conquistada e os negros continuaram excluídos da propriedade das terras.

O reconhecimento das comunidades quilombolas aconteceu somente após a promulgação da Constituição Federal de 1988, um século após o fim da escravidão, que 
reconheceu a importância da cultura e da identidade da população negra reconhecendo o direito à propriedade definitiva de suas terras.

No entanto, de acordo com dados do INCRA, apenas um pequeno número de comunidades remanescentes de quilombo teve suas terras regularizadas. $\mathrm{O}$ baixo número de regularização fundiária das terras quilombolas podem estar ligado aos conflitos envolvendo proprietários que compraram, invadiram ou grilaram as terras pertencentes aos quilombolas e que envolvem indenização.

Além dos conflitos envolvendo grileiros, invasores e proprietários que compraram terras dos próprios quilombolas, o processo de regularização fundiária esbarra na resistência de alguns membros das comunidades que recusam anexar suas propriedades em um título coletivo. Essa recusa se dá porque têm medo que os outros membros da comunidade invadam sua propriedade. Este fato está dificultado a titulação de diversas comunidades quilombolas do Estado do Tocantins e outros Estados do Brasil.

Quanto às comunidades remanescentes de quilombolas, estas são populações negras que vivem no meio rural e se auto identificam como Comunidades Negras Rurais, Terras de Preto, Quilombolas, Mocambos e outras designações correlatas. Se autodefinem a partir das relações com a terra, o parentesco, o território, a ancestralidade, as tradições e práticas culturais próprias. Conforme o artigo $2^{\circ}$ do Decreto 4.887 de novembro de 2003 ,

\footnotetext{
Consideram-se remanescentes das comunidades dos quilombos, para os fins deste Decreto, os grupos étnico-raciais, segundo critérios de auto-atribuição, com trajetória histórica própria, dotados de relações territoriais específicas, com presunção de ancestralidade negra relacionada com a resistência à opressão histórica sofrida BRASIL, 2003, p. or).
}

Nesse sentido, é a própria comunidade que se autorreconhecem como "remanescente de quilombo" sendo, também, um segmento da população negra brasileira marcada pela resistência, organização e, principalmente, pela luta em defesa de direitos sagrados: Terra, Liberdade, Cidadania e Igualdade.

Ao longo da sua trajetória, no Brasil, esse segmento resistiu de várias formas a um processo constante de tentativas de retirar seus direitos enquanto cidadãos, sendo que a principal delas ameaça os próprios territórios em que efetivamente moram e trabalham (ALMEIDA, 2002). Confundidas, como quilombos, essas comunidades negras, segundo Fiabani (2005), "[...] nas primeiras décadas após a abolição, não despertou o interesse sistemático das ciências sociais brasileiras" (FIABANI, 2005, p. 27).

Nesse sentido, apesar de estarem presentes na história brasileira desde a sua ocupação pelos europeus, pouco se conhece sobre os quilombos do passado e as comunidades negras rurais do presente. As comunidades negras rurais tiveram mais evidência na história brasileira a partir da promulgação da Constituição Federal de 1988 que no artigo 68 das Disposições Gerais, afirma que "[...] aos remanescentes das comunidades dos quilombos que estejam ocupando suas terras é reconhecida a propriedade definitiva, devendo o Estado emitir-lhes os títulos respectivos" (BRASIL, 1988, p. 158). E afirma ainda que "[...] ficam tombados todos os documentos e os sítios detentores de reminiscências históricas dos antigos quilombos" (BRASIL, I988, p. 76). 
É importante frisar que a partir da promulgação da Constituição Federal de 1988, a questão quilombola foi recolocada no contexto nacional com a "descoberta das comunidades quilombolas". Esse fato se deve à luta do movimento negro contemporâneo e ao exercício intelectual de vários intelectuais negros. A mobilização política das entidades que representam os negros culminou na publicação de um artigo das Disposições Transitórias dessa Constituição de 1988, dando direito à titulação das terras ocupadas.

Mesmo apontado na Constituição Federal de 1988 que é reconhecida a propriedade das terras ocupadas pelas comunidades negras, isso na prática não acontece. A luta é intensa pelo reconhecimento de suas terras. A identificação e configuração territorial das comunidades quilombolas do Brasil envolvem questões de ordem política e técnica.

Seu reconhecimento formal exige a análise da realidade vivencial a partir dos critérios: uso sustentável da terra, destino da produção, vínculo territorial, situação fundiária, organização social, expressões culturais e inter-relações com outros grupos da região (INCRA, 2013, p. or).

Sobre o início da regularização de uma área remanescente quilombola o Incra (2013), afirma que há a necessidade da:

[...] abertura do processo administrativo no âmbito do INCRA, devidamente autuado, protocolado e numerado. $\mathrm{O}$ processo poderá ser iniciado de oficio pelo INCRA ou a requerimento de qualquer interessado, das entidades ou Associações representativas de quilombolas. Pode ser feito pela simples manifestação da vontade da parte, apresentada por escrito ou verbalmente, caso em que será reduzida a termo por representante do INCRA (p. or).

O primeiro passo para reconhecer e regulamentar a terra quilombola é fundar e regularizar a associação da comu nidade quilombola, pois ela irá representa-los juridicamente em todo o processo de regularização e titulação do território. O título do território sairá no nome da associação da comunidade, pois a terra passará a ser coletiva. Após essa primeira etapa, a associação da comunidade solicitará ao INCRA a regularização do território que abrirá um processo.

Após iniciado o processo de regularização fundiária é emitido, pelo INCRA, um relatório técnico identificando e delimitando o território quilombola reivindicado pelos remanescentes. Esse relatório deve abordar as:

[...] informações cartográficas, fundiárias, agronômicas, ecológicas, geográficas, socioeconômicas, históricas e antropológicas, obtidas em campo e junto a instituições públicas e privadas, sendo composto pelas seguintes peças: relatório antropológico; levantamento fundiário; planta e memorial descritivo do perímetro da área reivindicada pelas comunidades remanescentes de quilombo, bem como mapeamento e indicação dos imóveis e ocupações lindeiros de todo o seu entorno; cadastramento das famílias remanescentes de comunidades de quilombos; levantamento e especificação detalhada de situações em que as áreas pleiteadas estejam sobrepostas a unidades de conservação constituídas, a áreas de segurança nacional, a áreas de faixa de fronteira, terras indígenas ou situadas em terrenos de marinha, em outras terras públicas arrecadadas pelo INCRA ou Secretaria do Patrimônio da União e em terras dos estados e municípios; parecer conclusivo (INCRA, 2013, p. I). 
Após esse estudo amplo, se tudo for comprovado, é emitido um título reconhecendo a comunidade como remanescente quilombola ou comunidade negra rural.

\section{COMUNIDADES REMANESCENTES DE QUILOMBOS NO TOCANTINS: SUAS LUTAS E CONQUISTAS}

Quanto ao Estado do Tocantins, este recebeu uma grande leva de escravos durante o ciclo do ouro no século XVIII. Silva (1998) afirma que os negros escravizados foram trazidos para a região para trabalhar na mineração "modalidade urbano-aurífero". Para Silva (1998), os escravizados viviam numa "nova sociedade dotada de organização social ainda mais rígida e o regime de trabalho indiscutivelmente pior" (1998, pg. 370).

O certo é que o Estado do Tocantins recebeu milhares negros escravizados durante o ciclo do ouro levando o Estado a ter a grande maioria da sua população composta de afrodescendentes. Segundo dados do IBGE (BRASIL, IBGE) Estado do Tocantins, 20I8), a população tocantinense estimada para 2018 é de 1.555,229 habitantes e, desse total, cerca de $75 \%$ são de pretos e pardos e a maioria vivem, principalmente, nos municípios que tiveram grande exploração de ouro no período colonial.

Segundo dados oficiais da Secretaria Estadual de Cidadania e Justiça ${ }^{4}$, no Estado do Tocantins existem, atualmente, 44 comunidades remanescentes de quilombos reconhecidas ou certificadas como tais. Apesar de existir um grande número de sujeitos remanescentes dos antigos quilombos e comunidade rurais negras, existe uma grande lacuna bibliográfica sobre esses aspectos no Tocantins. Nesse sentido, o que se tem escrito sobre a história desses aspectos se resume apenas a poucas comunidades que foram estudadas por alguns pesquisadores.

No entanto, no Estado do Tocantins existem comunidades remanescentes de quilombos e coletividades negras rurais que não são a mesma coisa. Remanescentes de quilombos são aqueles sujeitos descendentes de ex-escravos que fugiram do cativeiro e reuniram-se em um determinado local geograficamente estratégico para a defesa e formaram um reduto chamado de quilombo. Já as comunidades negras rurais foram formadas por sujeitos que, após o fim da escravidão, procuraram redutos isolados para se estabilizarem.

Há, também, aqueles que receberam terras do governo durante a escravidão como título de indenização por terem contribuído de alguma forma para o País (OLIVEIRA; PIRES, 2006). Um exemplo disso é a comunidade denominada de Barra da Aroeira, situada no Tocantins.

Ela é uma comunidade negra rural e não quilombola, pois, seus moradores são remanescentes da Guerra do Paraguai (I864-1870). As terras foram doadas a um soldado negro que "[...] teria voltado da Guerra do Paraguai e recebido uma doação de terras no lugar, hoje, denominado região do Jalapão, local onde vivia antes da Guerra. O doador teria sido D. Pedro II, imperador do Brasil" (OLIVEIRA; PIRES, 2006, p. 77).

A comunidade Barra da Aroeira trás características idênticas às outras comunidades negras ou quilombolas, ou seja, ficam distantes dos centros urbanos e de difícil acesso. Vivendo praticamente isoladas, essas comunidades vivem daquilo que produzem e retiram

\footnotetext{
4 https://cidadaniaejustica.to.gov.br/noticia/2018/I/5/cresce-numero-de-comunidades-certificadas-comoremanescentes-de-quilombos-no-tocantins/. Acesso em 26/II/2020.
} 
da terra, ou seja, nos arredores próximos de suas casas "[...] eles plantam arroz, feijão, mandioca, milho, cana-de-açúcar, maxixe, abóbora, manga, mamão, tamarindo, laranja e colhem produtos nativos da região, como macaúba, buriti e pequi” (OLIVEIRA; PIRES, 2006, p. 77).

A comunidade, apesar de ser reconhecida pelos órgãos oficiais, passa por questões fundiárias. A questão está no tamanho da terra reconhecida pelo governo como comunidade quilombola. A comunidade reivindica uma extensão muito maior de terras que, segundo eles, foram griladas. Oliveira e Pires (2006) afirmam que "os documentos referentes à doação das terras, segundo os relatos, sumiram em mãos de um advogado que teria assumido o trabalho de legalização fundiária” (OLIVEIRA; PIRES, 2006, p. 77).

Quando se fala em questões fundiárias envolvendo as comunidades quilombolas ou rurais retoma-se a retórica do direito constituído e negado para os sujeitos históricos que vivem nesses locais específicos. Muitas comunidades quilombolas podem ter desaparecidas do mapa por questões fundiárias. As comunidades que ainda existem podem ser consideradas remanescentes e sobreviventes de um processo histórico que demanda preocupação em ser preservado.

A luta é grande e os processos de regularização fundiária das comunidades quilombolas do Estado do Tocantins, mesmo com Leis consolidando esse direito, anda a passos lentos envolvendo grande burocracia estatal ou conflitos envolvendo a posse das suas terras.

\section{CONSIDERAÇÕES FINAIS}

Quando se fala em questões fundiárias envolvendo as comunidades quilombolas ou rurais retoma-se a retórica do direito constituído e negado para os sujeitos históricos que vivem nesses locais específicos. Muitas comunidades quilombolas podem ter sumidas do mapa por questões fundiárias. As comunidades que ainda existem podem ser consideradas remanescentes e sobreviventes de um processo histórico que demanda preocupação em serem preservadas.

O embate é grande em torno do reconhecimento dos seus direitos e, principalmente, a regularização fundiária das suas terras que foram surrupiadas por invasores, grileiros e por questões internas envolvendo os próprios quilombolas.

A existência de uma comunidade quilombola evidencia a importância das suas terras, essa é uma ponte de grande relevância para se fazer um resgate cultural desses grupos, evidenciando a importância de integrar ferramentas ricas no sentido de apontar a necessidade de regularizar suas propriedades. Nesse sentido, é preciso reconhecer as identidades e as novas possibilidades do exercício de direitos e cidadania plena dos negros.

Deve romper com a impossibilidade em reconhecer a importância da contribuição da memória e resistência negra na sociedade contemporânea. É preciso valorizar a importância da transmissão dos valores culturais, formação e troca de saberes, resgatando a cultura do povo negro por meio de ações efetivas de preservação e valorização de espaços de tradição das comunidades rurais negras.

Entender que nas comunidades quilombolas se prática a resistência, uma luta contra a intolerância, o racismo, por meio da preservação da identidade e manifestações culturais que precisam ser protegidas. Ainda se convive com a precarização desses espaços que resistem a todas as intempéries, a uma sociedade e um Estado que não respeitam a pluralidade e a 
diversidade de sua formação. Uma sociedade que convive com intolerâncias e preconceitos dos que não conseguem interagir com espelhos que refletem muitas verdades sendo que nenhuma delas é verdade absoluta.

\section{REFERÊNCIAS BIBLIOGRÁFICAS}

ALMEIDA, Alfredo Wagner Berno de. Terras de Preto no Maranhão: Quebrando o Mito do Isolamento. São Luís - MA: Coleção Negro Cosme- vol. III, 2002.

BRASIL. Constituição Federal do Brasil de 1988. Disponível em:

http://www.senado.gov.br/legislacao/const/conı988/CONi988_05.10.1988/CONi988.sht m. Acesso em oI/II/2020.

BRESSER-PEREIRA, Luiz Carlos. Desenvolvimento, progresso e crescimento econômico. Lua Nova [online], n. 93, p.33-60, 2014, Disponível em: https://www.redalyc.org/articulo.oa? id=67335779003

Decreto n. ${ }^{\circ} 4.887$ de 20 de novembro de 2003. Disponível em: http://www.planalto.gov.br/ccivil_03/decreto/2003/d4887.htm. Acesso em 23/o9/2013.

- Instituo Nacional de Colonização e Reforma Agrária. Disponível em: http://www.incra.gov.br/index.php/estrutura-fundiaria/quilombolas/file/rog-quadroatual-da-politica-de-regularizacao-de-territorios-quilombolas-no-incra. Acesso em $02 / \mathrm{II} / 2020$.

Estado do Tocantins. Secretaria da Cultura. Disponível em: https://cidadaniaejustica.to.gov.br/noticia/2018/1/5/cresce-numero-de-comunidadescertificadas-como-remanescentes-de-quilombos-no-tocantins/. Acesso em 20/II/2020.

FIABANI, Aldemir. Mato, palhoça e pilão: o quilombo, da escravidão às comunidades remanescentes. São Paulo: Expressão Popular, 2005.

MAESTRI, Mário. Uma defesa do quilombo. 2005 (mimeo)

PIRES, Antônio Liberac Cardoso Simões e OLIVEIRA, Rosy. Notas etnográficas sobre as comunidades negras rurais do Tocantins. IN: Pires, Antônio Liberac Cardoso Simões e Oliveira, Rosy (Orgs.). Sociabilidades negras: comunidades remanescentes, escravidão e cultura. Belo Horizonte: Editora Gráfica Daliana Ltda, 2006.

PILETTI, Nelson. História do Brasil. São Paulo: Ática, I991. 
SANTOS, Vilson Pereira dos. Técnicas da tortura: punições e castigos de escravos no brasil escravista. ENCICLOPÉDIA BIOSFERA, Centro Científico Conhecer - Goiânia, v.9, N.16; p. 2394, 2013.

SILVA, Martiniano José da. Quilombos do Brasil Central: séculos XVII e XIX (I719 - I888) - Instituto ao estudo da escravidão. 1998. 464f. Dissertação (Mestrado em História) Instituto de Ciências e Letras, Universidade Federal de Goiás, Goiânia, 1998. 